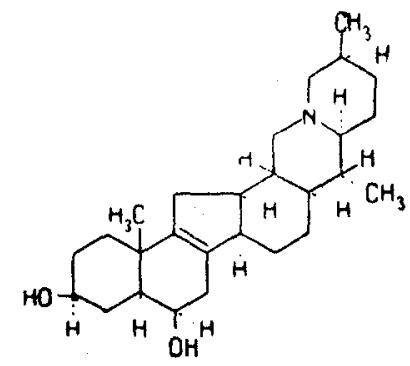

\title{
REFERENCES
}

1. R. N. Nuriddinov, A. I. Saidkhodzhaev, and S. Yu. Yunusov, KhPS [Chemistry of Natural Compounds], 4, $161,1968$.

2. R. N. Nuriddinov and S. Yu. Yunusov, KhPS [Chemistry of Natural Compounds], 3, 98, 1967.

3. R. N. Nuriddinov and S. Yu. Yunusov, KhPS [Chemistry of Natural Compounds], 4, 258, 1968.

4. R. N. Nuriddinov and S. Yu. Yunusov, KhPS [Chemistry of Natural Compounds], 4, 390, 1968.

5. R. N. Nuriddinov, R. Shakirov, and S. Yu. Yunusov, KhPS [Chemistry of Natural Compounds], 3, $316,1967$.

6. R. N. Nuriddinov and S. Yu. Yunusov, KhPS [Chemistry of Natural Compounds], 4, 334, 1968.

7. R. N. Nuriddinov, A. I. Saidkhodzhaev, M. R. Yagudaev, and S. Yu. Yunusov, KhPS [Chemistry of Natural Compounds], 4, 333, 1968.

22 May 1968

Institute of the Chemistry of Plant Substances, AS UzSSR

UDC $547.94+547.965$

\section{ALKALOID CONTENT OF SOME PLANTS OF THE FAMILY LABIATAE}

\section{T. P. Pulatova}

Khimiya Prirodnykh Soedinenii, Vol. 5, No. 1, pp. 62-63, 1969

We have studied 30 species of plants of the family Labiatae growing in Uzbekistan for their alkaloid content; 15 of them gave a positive reaction for alkaloids. As a result of the quantitative determination and isolation of nitrogen bases by the chromatographic method (on a column of neutral alumina), we obtained two fractions. The first fraction (elution of the bases with 10-20\% solutions of ethanol in chloroform), consisted of stachydrine and the second (elution with $20-$ $40 \%$ solutions of ethanol in chloroform), consisted of liquid bases.

The amounts (\%) of stachydrine were: in Marrubium alternidens Rech., 1.16; in Sideritis montana L., 0.82; in Eremostachys speciosa Rupr., 0.35; in Lamium album L. (white deadnettle), 2.01; in Leonurus turkestanicus V. Krecz et Rupr., 1.5; in Lagochilus setulosus Vved., 1.3; in L. Pubesceus Vved. , 0.71; in L. inebrians Bge., 0.52 ; in L. platycalyx Schrenk. , 1.45; in Stachys betoniciflora Rupr. , 0.74; in S. hissarica Rgl., 0.47; and in Scutellaria immaculata Nevsci ex Juz, traces.

The amount of liquid bases in these plants varied from 0.14 to $3.29 \%$, apart from Lagochilus platycalyx Schrenk. , where they were absent.

In the qualitative investigation of the bases isolated by the method of descending chromatography on paper of type FN-3 (rnedium speed) a base was found with $\mathrm{R}_{f} 0.33$ in system 1 [1-butanol-acetic acid-water $\left.(4: 1: 5)\right]$ and $\mathrm{R}_{f} 0.88$ in system 2 (15\% acetic acid). This base was shown to be identical with an authentic sample of stachydrine. A base with $\mathrm{Rf}_{\mathrm{f}} 0.22$ was shown chromatographically to be identical with choline. The latter was found in six plants.

A base with $R_{f} 0.37$ in system 1 was found in all the plants except L. platycalyx and one with $R_{f} 0.43$ in system 1 in six plants.

Characteristic of Lagochilus Bge. from the section Inermus is a base with $R_{f} 0.9$ (system 1 ) and 0.8 (system 2 ) - a white crystalline substance readily soluble in methanol, ethanol, and acetone, and sparingly soluble in water, not fluorescing in UV light, $\mathrm{mp} 105^{\circ} \mathrm{C}$. The study of this base is continuing.

Thus, in an investigation of plants of the family Labiatae we have found stachydrine, choline, and unknown bases. 